\title{
EDUCAÇÃo E PERSONALIDADE: o afeto e a formação do poder no grupo familiar
}

\author{
EDUCATION AND PERSONALITY: affection and training of power \\ in the family group
}

Armando Marino Filho (UNESP - Marília)

\begin{abstract}
Resumo: Pretende-se com esse trabalho refletir sobre a importância da atividade familiar na formação dos indivíduos para o futuro de suas relações. Considera-se que o processo educativo deve dirigir-se para a formação omnilateral, e que o grupo e a atividade comunicativa são formas de organização coletiva fundamentais para o desenvolvimento da personalidade. Para tanto, faz-se uma exposição de conceitos da teoria Histórico-Cultural para que se possa compreender como as capacidades psicológicas e a afetividade conferem poder aos indivíduos. Assim, avalia-se a estrutura da atividade social como forma de aquisição do poder que, condicionado pelo entorno, proporciona um determinado desenvolvimento para a personalidade. Pode-se considerar, portanto, como síntese da relação grupal familiar, a educação da personalidade como foco fundamental de sua atividade. Conclui-se, então, que a organização da atividade educativa no seio familiar é prenúncio das possibilidades da formação crítica para a atividade social dos indivíduos como sujeitos das transformações sociais necessárias ao desenvolvimento cultural.
\end{abstract}

Palavras-chave: Educação. Personalidade. afetividade.

Abstract: It is intended with this work reflect on the importance of family activity in the formation of individuals for their future relationship. It is considered that the educational process must go for formation equilateral, and that the group activity and communicative forms of collective organization are fundamental to the development of personality. For this, it is an explanatory concepts of CulturalHistorical theory, so that you can understand how the psychological and affective skills to empower individuals. Thus, we evaluate the structure of social activity as a means of acquiring power, conditioned by the environment, provides a particular development to personality. It can be considered therefore as synthesis of group relationships, family education of the personality as fundamental focus of their activity. It follows then that the organization of educational activities within the family is harbinger of the possibilities of training critical to the social activity of individuals as agents of social transformation necessary for cultural development.

Keywords: Education. Personality. affection.

\section{Introdução}

Uma análise da atividade familiar como atividade humana grupal, requer que se compreenda a formação de qualquer grupo como organização da atividade viva, que complexificando-se exige um constante processo de reorganização e orientação dos seus processos.

A atividade vital que concerne à produção e manutenção da vida complexifica-se até que no homem essa se transforma de fundamentalmente individual em coletiva. Por isso, para se compreender o desenvolvimento humano e as formas de orientação da sua atividade - que no animal se dá como relação direta com o ambiente, mas para o homem passa a orientar-se mediadamente pelos significados sociais - é importante o entendimento dos processos grupais educativos.

É necessário compreender-se como a motivação para as ações manifestam um poder que não se reduz a forças materiais, biológicas. A motivação e seu poder estão intrinsecamente ligados à formação de capacidades que só podem efetivar-se na atividade coletiva como processo educacional. 
Além disso, ocorre que a atividade vital humana é caracterizada por formas que se sobrepõem àquela causada pela imediata relação sensível do homem com o mundo material. Isso quer dizer que sobrevém para o homem a vivência, ou experiência viva, em planos de relações que ultrapassam a sensibilidade e alcançam a esfera das relações simbólicas. Desse modo, a significação que orienta o comportamento humano só existe como forma coletiva, já a afetividade adquire a qualidade das relações com outros seres humanos.

Essa condição para a afetividade que produz um tipo especial de representação simbólica orientadora do comportamento, que se desenvolve a partir da valorização do lugar ocupado nas relações grupais, na forma de poder para atuar como membro de uma comunidade. Assim, surge para os indivíduos, sujeitos das atividades grupais, novas necessidades afetivas que irão caracterizar a particularidade do seu processo de individuação humana.

Nesse processo de formação particular de desenvolvimento humano social, por meio da aquisição de capacidades psicológicas superiores - as biológicas e hereditárias que adquiriram novas qualidades produzidas pela cultura - forma-se um novo tipo de expressão subjetiva do psiquismo, que chamamos personalidade. Segundo Vigotski (2000, p. 327) é uma neoformação produzida pela atividade cultural e tem como princípio a tomada de consciência das suas relações individuais na coletividade.

A personalidade, portanto, está diretamente relacionada com as condições e situações nas quais ocorre o processo educativo e em atividade grupal. A relação "eu/outro" na complexidade da produção da vida, evidencia-se como fundamental para a formação de sentidos pessoais que imprimem uma forma de relacionamento social. Assim, durante a sua atividade e diante das problemáticas objetivas e subjetivas que esta suscita, um posicionamento do indivíduo é exigido como forma de expressão do seu pertencimento à comunidade. Nesse momento revela-se a sua personalidade e esta implica alterações nas condições e situações da realidade coletiva.

Compreende-se, dessa forma, que a personalidade é escopo principal da atividade educativa, haja vista, que é por meio da sua manifestação que os indivíduos participam das transformações sociais e culturais que alteram sobremaneira a sua vida e a dos outros.

Assim, a compreensão da estrutura da atividade encaminha o pensamento para a compreensão do grupo familiar e a formação psicológica dos indivíduos. Isso possibilita compreender como ocorre a dinâmica das relações interpessoais e como essas se transformam subjetivamente em capacidade de orientação individual nas relações coletivas. Acrescentado que, a melhor capacidade crítica em relação a si próprio e à sociedade advêm do desenvolvimento das capacidades do pensamento, mas também, da equilibrada formação e desenvolvimento constante da personalidade.

\section{Atividade social e educação}

A atividade humana tem como consequência a criação de necessidades, isto é, uma condição criada na própria atividade. A necessidade é constituída com as características da situação na qual foi criada e apresenta-se como um aspecto do qual depende o desenvolvimento da atividade. Sendo assim, ela orienta, de certa forma, os rumos que a atividade deve tomar.

Outra característica da atividade é que ela gera, também, necessidades de novas atividades, ou seja, cria novas atividades. As problemáticas ou contradições que surgem 
em uma atividade podem referir-se também a outras esferas da vida de um indivíduo e, com isso, a sua solução pode depender do desenvolvimento de outros recursos que demandam uma nova atividade.

Assim, a existência de uma atividade gera em determinadas circunstâncias a criação de novas atividades e marca o processo de desenvolvimento e complexificação da vida de um indivíduo, porque as atividades criadas vão se entrelaçando e criando vínculos cada vez mais intricados que em cada momento sintetizam em si, a própria forma do desenvolvimento do indivíduo. Nesse sentido, o desenvolvimento de um indivíduo é marcado pelo desenvolvimento de suas atividades. Vale ressaltar, então, que a orientação e a forma que se dá para as atividades de um indivíduo, determinam em certo modo as possibilidades do seu desenvolvimento.

No entanto, a necessidade não subsiste por si mesma. Toda necessidade só faz sentido com a existência do seu objeto (LEONTIEV, 1978, p. 152), isto é, aquilo que se transformou em algo sem o qual a situação não encontra resolução ou a continuidade do ser fica ameaçada. Assim, a condição da existência de uma necessidade é a possibilidade da existência do seu próprio objeto, isto é, aquilo que é necessário. Toda necessidade, portanto, tem um "outro" que a completa.

Encontrar o que é o necessário é o ponto de partida para a motivação, para o surgimento de ações e operações para a consecução de uma atividade. (LEONTIEV, 1978, p. 148). Junto com isso, ainda encontramos como condição básica da estruturação das atividades, a existência de condições objetivas e instrumentais que possibilitam a efetivação das condições cognitivas e intelectuais do pensamento, na atividade.

Ao nascer, por exemplo, uma criança será inserida nas atividades do grupo familiar, tanto aquelas que estão diretamente ligadas aos cuidados com sua vida, quanto aquelas das quais ela participa sem haver para si uma necessidade a priori. Essas duas espécies de grupos de atividades causarão na criança novas necessidades que não fazem parte daquelas que são próprias da sua existência biológica.

A atividade da criança, nesse caso, começará a constituir-se com os conteúdos objetivos e afetivo e emocionais que são próprios do grupo e da cultura na qual ela passa a existir. O seu comportamento começará a adquirir as qualidades das relações sociais que orientarão a forma de desenvolvimento das suas qualidades psicológicas intelectuais, do pensamento e da personalidade. (LEONTIEV, 1998, p. 82).

O conjunto dos elementos constituintes da atividade configura-se, em sua totalidade, como um sistema de orientação e controle que expressa a própria condição viva. Assim, uma noção importante - ainda que precária, mas imprescindível - é que o psiquismo representa esse sistema que só pode caracterizar-se pela própria atividade.

É assim que há uma comunidade de estrutura, ainda que seja diferente na sua existência, entre a atividade objetiva - atividade motora de trabalho constituída de ações e operações instrumentais - e a subjetiva - atividade intelectual do pensamento, constituída de ações e operações simbólicas. A intrínseca relação entre essas esferas da atividade se dá pelo fato de que ambas orientam a atividade humana. Por exemplo, os resultados da atividade motora representam de certa forma o teste da realidade dos planejamentos e antecipações feitas pelo pensamento, que são próprios das ações. Por outro lado, a atividade intelectual do pensamento analisa e sintetiza o conjunto das relações e de que forma estas afetam a produção da atividade e a existência do ser na condição dada, isto é, avalia a vivência da atividade, atribuindo-lhe um valor e um significado. 
As respostas dadas pela realidade objetiva e pelas avaliações do pensamento constituem o conjunto de informações com os quais operam as funções psicológicas superiores. Isso significa que esse conjunto de informações forma o conteúdo do sistema de orientação e controle que, por sua vez são constituídos na própria atividade. Portanto, deve-se compreender que as formas de orientação e controle da atividade de um sujeito, manifestam-se como formas adquiridas e produzidas no conjunto de suas atividades, são produto destas e de sua auto-atividade avaliativa dos resultados de suas ações e das dos outros. É isso que vem constituir a formação do sentido pessoal orientador dos atos e atitudes do sujeito de uma ação.

Como atividade coletiva - compreendendo coletividade como conjunto de diversos grupos sociais - a orientação representa um conjunto de interesses diversos para a produção da vida social. Nesse sentido, compreende-se que o sistema de orientação da coletividade social é dado tanto pela prática produtiva - seu resultado material - quanto pelo processo de produção de signos que possibilitam a conjunção dos diferentes grupos de indivíduos na atividade comunicativa.

Assim, a atividade comunicativa é outro elemento formador da base de desenvolvimento humano social por meio da atividade. Como disse Leontiev (1978, p. 170),

\begin{abstract}
A comunicação, na sua forma exterior inicial, enquanto aspecto da atividade coletiva dos homens, isto é, sob forma de "coletividade direta" ou sob uma forma interior, interiorizada, constitui a segunda condição específica indispensável do processo de apropriação pelos indivíduos dos conhecimentos adquiridos no decurso do desenvolvimento histórico da humanidade.
\end{abstract}

A linguagem, então, como meio de realização da comunicação é fundamental na organização da atividade, e por isso, considerando a relação entre a atividade objetiva e a subjetiva, tem na mesma medida, importância para a organização e orientação do psiquismo. É com a linguagem que será possível o processo de transmissão das informações necessárias ao processo educativo. Assim, ela ocupa um lugar privilegiado nessa atividade, não somente pelo fato de viabilizar o conhecimento, mas também, porque é constituinte dos processos de significação e formação dos sentidos pessoais. Como disse Vigotski (2001, p. 11) "A linguagem é antes de tudo, um meio de comunicação social, de enunciação e compreensão."

Deve-se destacar esse caráter enunciativo da linguagem quando se trata de considerar o caráter afetivo causado pela utilização da palavra no ato comunicativo. A palavra, como disse o mesmo autor,

[...] é uma generalização latente, toda palavra já generaliza e, em termos psicológicos, é antes de tudo uma generalização. Mas a generalização, como é fácil perceber, é um excepcional ato verbal do pensamento, ato esse que reflete a realidade do modo inteiramente diverso daquele como esta é refletida nas sensações e percepções imediatas. (VIGOTSKI, 2001, p. 9).

Sob esse aspecto, a palavra enunciada pelo educador, além de generalizar o mundo dos objetos, também insere a criança em relações de categorização quando se refere a dizer para ela qual o seu poder, em que esferas da vida e como pode realizar suas necessidades e interesses. Esse ato de inclusão em um determinado gênero afeta 
consideravelmente a autoestima $\mathrm{e}$, portanto, o autoconceito da criança em relação à concepção de mundo que vai construindo. Portanto, na educação da personalidade.

Do mesmo modo que quando o educador generaliza a existência da criança quando enuncia uma palavra que a afeta, a criança ao proferir palavras enuncia a compreensão do lugar que ocupa nas relações de poder, e como isso a afeta, qual é o sentido pessoal do seu significado. Portanto, expressa o valor pessoal das suas relações em uma dada esfera e, assim, expressa a sua personalidade.

\section{Aspectos da educação como atividade}

A educação é uma atividade. Isso quer dizer que se estrutura com ações e operações que tem uma meta, uma intencionalidade e é, por isso, objetivada. Isso quer dizer que é direcionada a um objetivo simbólico tanto quanto produz alterações na realidade.

Como toda atividade, pode ser planeja racionalmente e elaborada de forma lógica por meio de conhecimentos sistematizados historicamente. A educação nesses termos seria uma atividade racionalizada para fins objetivos esclarecidos. No entanto, imaginar uma educação que pudesse realizar-se exclusivamente nesses termos seria uma ilusão. Em toda atividade o ser humano existe como totalidade. Assim, todos os aspectos afetivos, emocionais e cognitivos encontram-se ao mesmo tempo no homem esteja ele onde estiver e em que situação for.

Ao pensar-se a atividade educativa e quais sejam os seus objetivos encontrar-seá o homem, a sociedade e a cultura como meta, como finalidade objetivada. É dessa relação entre sujeitos de uma atividade que ocorre na atividade grupal que trata a compreensão da educação da personalidade como poder. A estrutura da atividade grupal é caracterizada pelo fato de que as ações são divididas entre os seus sujeitos. Assim, cada um age em direção a uma meta definida pela própria ação, mas com um objetivo comum definido pela atividade.

Pode-se imaginar que o adulto educador divide as ações entre si e a criança, que esclarece a esta quais sejam as ações que deve realizar. Ao fazer isso tem em mente uma motivação da qual a criança só pode compreender parcialmente, pois não possui o domínio dos significados, não é capaz para compreender a motivação da atividade adulta, e, sempre que isso ocorre há uma alteração no lugar que ocupa na atividade, passa de sujeito a objeto.

O adulto, ao tratar a criança como objeto da sua atividade, cria para esta uma situação paradoxal, a de sujeito e objeto de uma mesma atividade. Tal contradição afeta sobremaneira a compreensão de si no mundo social. Em muitas ocasiões os adultos agem de forma contraditória, fazendo coisas que são possíveis para a criança, mas que só permitido para o adulto, por exemplo, fumar, mentir etc. Essa situação de objetificação da criança não muda somente a sua posição na atividade, mas a meta da ação do adulto. Ao objetivar uma ação a sua meta torna-se específica, direciona-se a aspectos isolados e muito pontuais, pode, inclusive, servir a interesses particulares.

Em todo ato educativo, ambos os pólos, eu e outro, adulto e criança, revelam ativa e passivamente as suas necessidades. Assim, o que se apresenta no ato educativo é o mundo dos seus atores em plena confluência e contradição entre necessidades e motivos da atividade grupal e individual. O educador ao enunciar o mundo como o compreende, expressa uma visão de mundo social que inclui suas experiências pessoais e os valores afetivos. Isso ocorre nos atos comunicativos, nos gestos, nas expressões, na 
intensidade da voz, na ênfase dada aos aspectos particulares de cada assunto, etc. A criança caminha com ele nesse mundo objetivado por atos concretos e simbólicos, por representações materializadas e imaginadas.

Por outro lado, a mesma criança que de alguma forma acompanha o adulto em uma situação educativa, vive contraditoriamente o mundo real da sua afetividade e o mundo concreto das exigências sociais. A possibilidade de compreensão do fim teleológico da atividade do adulto está sempre comprometida pela existência de um mundo estranho, distante e muitas vezes imperceptível. No processo de formação da consciência, criança vive sempre essa situação alheamento dos fins últimos das intenções dos adultos.

Ao considerar, então, na dinâmica da atividade familiar o processo educativo, encontraremos uma diversidade de situações educativas em função do lugar que a criança ocupa, por exemplo, se tem irmãos mais velhos e mais novos, pais presentes, outros parentes próximos, e como ocorre toda sorte de relações de poder e diferentes valores. Não é difícil perceber a complexidade de contradições que a criança vive quando está sujeito aos atos educativos por uma multiplicidade de sujeitos que, por sua vez, vão formando certa representação, muitas vezes caótica, do mundo.

Se a atividade coletiva é marcadamente organizada pela produção da vida material e pelos interesses materiais, por outro lado, na atividade grupal o que une os indivíduos é o valor da relação afetiva, esta ganha intensidade e ocupa um lugar privilegiado na hierarquia das atividades familiares. Assim, uma atividade relacional cujo dinamismo é dado pelo valor do afeto, ganha relevo no grupo familiar.

Portanto, na análise do desenvolvimento da personalidade a experiência da vida grupal tem muita importância, pois, a afetividade é a componente fundamental da personalidade, já que ela inter-relaciona o homem com o seu mundo. O grupo é de fundamental importância para o desenvolvimento humano, já que é nesse tipo de relação que o homem adquire as qualidades psicológicas necessárias para a participação na sociedade.

Cada indivíduo relaciona-se tanto com as determinações da sociedade, segundo o lugar que o seu grupo ocupa nas relações de produção, quanto com as determinações do próprio grupo em relação a si mesmo, segundo o lugar que ocupa neste. Assim, no grupo ocorre uma dupla determinação das possibilidades de relacionamento individual que são marcadas por diferentes interesses. Os processos que ocorrem no grupo familiar têm essa dupla orientação, de um lado, atendem às necessidades sociais mais amplas e de outro as necessidades individuais.

Como o ser de cada indivíduo humano somente se forma adquirindo-se as características das formas culturais, o grupo é a primeira condição espaço/temporal na qual isso ocorre. É por isso que o nível da vivência subjetiva ganha relevo nos pequenos grupos. É por meio da atividade dos pequenos grupos que o homem se prepara para a vida em grupos mais complexos na vida social.

No pequeno grupo, o indivíduo recebe as informações para compreender a existência de relações estranhas, que distantes de sua realidade imediata o afeta de um modo ou de outro. Sem a mediação do grupo é praticamente impossível qualquer indivíduo atingir o grau de consciência da sociedade na qual existe. No grupo se formam representações, ideias com as quais é possível orientar-se para o futuro, planejar o pertencimento a grupos desconhecidos por meio do pertencimento a um grupo atual. 
Assim, o pequeno grupo é inicialmente um modelo de relações que se generalizarão como sentido para as relações sociais mais amplas.

Será dessa forma, que ocupando um lugar nas relações sociais, o grupo torna-se meio de entrada das formações ideológicas sobre a vida social e o seu valor. O lugar do grupo nas relações circunscreve um conjunto de interesses correlacionados que, por sua vez, formam um conjunto de representações do mundo que amoldam, em certa medida, os interesses individuais.

No caso do grupo familiar, e para aquilo que nos interessa para essa reflexão, entende-se que de início é justamente os interesses afetivos que orientam a sua formação. Há, sem dúvida, um conjunto muito extenso de possibilidades de motivos para a formação de um grupo familiar. Podem ocorrer interesses materiais, imposições culturais, conveniências comerciais entre famílias, questões religiosas etc. No entanto, ao se unirem os cônjuges dão início a uma relação dinâmica configurada com aquilo que também os afeta emocionalmente. Então, para a nossa avaliação das consequências para a formação da personalidade da criança nesse processo educativo familiar, ter-se-á como ponto de referência que, quaisquer que sejam os motivos de formação do grupo familiar os seus sujeitos estarão envolvidos, principalmente, em uma teia de relações de interesses e motivos afetivos.

Essa noção é importante, já que o processo educativo que envolverá todos os aspectos e qualidades psicológicas, bem como as práticas sociais, serão mediadas por representações ideológicas da cultura social, pelos interesses particulares dos pais, como um ideal de formação que implica construções afetivas das experiências individuais.

Nesse ponto, vale considerar a atividade familiar que se direciona a formação dos seus filhos como sujeitos sociais. Faz parte da atividade familiar a manutenção de sua existência, formas de produção material e atividade cultural. Isso quer dizer que a família deve produzir ações que causem um efeito real na vida social para garantir ou alterar a sua posição na hierarquia das relações produtivas, para satisfazer as necessidades de seus membros. Assim, as formas de agir da família como um grupo são importantes na medida em que realizam objetivos sociais compatíveis com as suas aspirações, desejos e interesses.

Toda uma preparação dos filhos para representarem de um modo ou de outro um padrão socialmente aceito, será direcionado dentro da família como forma de manter uma coerência das ações dos seus membros. Para tanto, uma produção ideológica no interior da própria família surgirá como meio de manter a coesão entre seus membros, como esforço comum para alcançar os objetivos sociais.

A educação surgirá, nesse momento, como principal da atividade da família, isto é, cuidar-se-á de garantir a aprendizagem de determinados modos de ser, agir, pensar, sentir e orientar-se nas relações sociais, que reproduzam a forma dominante da própria família. A educação no interior da família, entretanto, ocorrerá circunstanciada por um sem fim de contradições, que inevitavelmente serão proporcionadas pela complexidade da existência do grupo familiar em suas relações com outros grupos sociais.

Em relação aos filhos pequenos essa educação será afetivamente carregada e ao passo que estes crescem e se aproximam da idade adulta, a predominância da relação educativa se volta para as questões produtivas da família e depois individuais. Essa alteração da posição de poder que a criança ocupa nas relações internas da família, altera da mesma forma o desenvolvimento e as manifestações de sua personalidade. Assim, a dinâmica da atividade familiar deve ser compreendida primeiro como processo

\begin{tabular}{|l|r|r|r|r|r|}
\hline Interfaces da Educ. & Paranaíba & v. 1 & n. 2 & p. 79-96 & 2010 \\
\hline
\end{tabular}


educativo da afetividade e, depois ou seja, da formação do sujeito social. Isso significa a educação de um sujeito social como portador de uma personalidade.

Assim, no âmbito familiar ocorre uma confluência de interesses que se não se apresentam uniformizados e homogêneos, representam da mesma forma uma diversidade que se confunde entre os do próprio grupo e os da sociedade na qual este existe. A humanização do indivíduo como unidade biopsicosocial ocorre nessa complexidade de interesses e contradições entre necessidades grupais e sociais, o que significa, que o indivíduo deverá se conformar em muitos aspectos a determinações impessoais. Como disse Mészáros (2005, p. 43-44)

\begin{abstract}
As determinações abrangentes do capital afetam profundamente cada domínio singular com algum peso na educação, e de forma alguma apenas as instituições educacionais formais. Estas últimas estão estritamente integradas na totalidade dos processos sociais. Elas não podem funcionar adequadamente, exceto se estiverem em sintonia com as determinações educacionais abrangentes da sociedade como um todo.

Aqui a questão crucial, sob a regra do capital, é assegurar a adoção por cada indivíduo das aspirações reprodutivas objetivamente possíveis da sociedade como 'o seu próprio objetivo'.
\end{abstract}

Considera-se aqui que o desenvolvimento das capacidades psíquicas representa, em relação à motivação, o poder para agir e assegurar de alguma forma a atividade vital humana, tanto no plano das relações materiais quanto no plano das relações psíquicas referentes ao mundo simbólico da cultura. Esse poder, que só se desenvolve no processo educativo, é o que se configura como possibilidade para a satisfação das necessidades pessoais. O que eu posso ou não realizar como efetivação da minha personalidade no âmbito da vida social, é determinado em grande medida por aquela confluência de interesses heterogêneos, pelo desenvolvimento das capacidades psíquicas e pela determinação impessoal, o que afeta o sentido pessoal de autorealização.

\title{
A atividade educativa e o poder
}

Como compreender quais sejam os objetivos da atividade educativa para o desenvolvimento do poder para relacionar-se socialmente? A educação, além de tudo o mais, causa um processo de superação da condição natural para uma cultural. Isso significa que o homem adquire qualidades não naturais como forma de poder realizar ações que, por sua vez, também não são naturais. Aqui a educação tem o sentido de empoderamento do ser, cria potencialidades.

Todas as formas do ser cultural que foram desenvolvidas historicamente, e que são aquelas que representam as relações materiais entre os homens, são transmitidas pelo processo educativo às novas gerações. O homem deve aprender como agir culturalmente no uso e instrumentos sociais. O seu poder para relacionar-se culturalmente depende fundamentalmente do ensino e da aprendizagem.

Mas, o que se ensina especificamente, que significa a aquisição de poder no plano psicológico? O poder natural conferido a cada indivíduo pela herança genética refere-se a que cada um tem à sua disposição uma base biológica formada pela filogênese. Isso permite a cada indivíduo uma atividade inicial relativa aos estímulos materiais por meio de respostas reflexas e instintivas já constituídas. Isso quer dizer que o poder inicial para agir está limitado por essa história da relação sensível e material de evolução do organismo biológico. 
Por outro lado, as relações efetivadas produzem alterações nas capacidades iniciais que estão relacionadas, no plano perceptivo, às alterações causadas no meio pela ação do indivíduo (VIGOTSKI, 2000, p. 86). O registro sensível dessas alterações no meio acrescenta novas qualidades que se fundem com as biológicas e representam uma nova formação baseada na atividade do indivíduo e que transforma o seu modo de relacionar-se com o mundo objetivo (DAVIDOV, 1988, p. 29). Mas isso significa que a aquisição dessas novas qualidades é suficiente para a superação do plano natural para o cultural? É evidente que não. Percebe-se facilmente que o homem por si só não desenvolve o poder para agir, que foi desenvolvido pela cultura humana e que existe na forma atual na sociedade na qual nasceu.

O poder para agir na sociedade e na sua forma cultural, depende da ação intencional de formação - mediação - das capacidades psíquicas desenvolvidas além do plano biológico e natural. São capacidades estranhas às biológicas? Não também. Como disse Vigotski (2000, p. 132) "A cultura não cria nada, tão somente utiliza o que lhe dá a natureza, o modifica e põe ao serviço do homem." É assim, então, que a reflexão sobre o desenvolvimento do poder para relacionar-se desta ou daquela maneira com a cultura social, passa pela compreensão de como ocorre essa transformação da natureza biológica por meio da atividade cultural.

Como vimos, a ação individual por meio das potencialidades naturais são suficientes para a aquisição das qualidades materiais sensíveis presentes na sua atividade, mas insuficientes para a aquisição das qualidades simbólicas de orientação com os instrumentos e atividades culturais. É justamente a atividade social, que é exigência para a transformação das qualidades naturais em culturais. As funções psicológicas superiores exigem uma atividade especial para o seu desenvolvimento, e esta não ocorre no plano individual, mas grupal.

A atividade grupal é a condição para o desenvolvimento dos poderes para agir humanamente. Nessa atividade as funções psicológicas como a memória, a atenção, o pensamento, a linguagem etc. adquirem novas qualidades que são exigências da atividade para a consecução de seus objetivos, como se viu acima.

Cada indivíduo, quando participa das ações e operações, usa instrumentos materiais e meios simbólicos - signos e significados - que guardam em si mesmos a história operacional, os objetivos racionalizados, uma lógica organizada pela comunicação que, em seu conjunto, altera as funções básicas do pensamento conferindo-lhes um novo poder.

É por isso que a educação se faz necessária como forma de transformação das funções psicológicas naturais para formas de poder historicamente constituídas, é necessário transmitir as formas operacionais dos instrumentos e da linguagem como forma lógica - organização discursiva do conhecimento -, para a organização, orientação e execução das ações. Ao difundir esses conhecimentos, eles se transformam em poder para os indivíduos, para se efetivarem como membros de um grupo.

\section{O poder como força motivacional}

O poder desenvolvido na atividade de ensino e aprendizagem, se traduz em seu conjunto como possibilidade motivacional. A motivação, nesse sentido, aparece como produto da atividade educativa e deve, como componente essencial da atividade humana, compor as características da personalidade. 
A motivação significa a emergência de um dinamismo direcionado por um sentido. Este, por sua vez, representa a concatenação: primeiro dos recursos psicológicos, como capacidades psíquicas superiores, afetos, conhecimentos, representações, imaginação; segundo, dos recursos materiais como, instrumentos, organização no espaço/tempo e condições objetivas, em função das características próprias do objeto de uma ação ou atividade; terceiro, como recursos motores, como força física e habilidades técnicas. Portanto, não basta reconhecer o objetivo da ação, é necessário coordenar as possibilidades concretas para a sua realização, para que o sentido da ação (motivação) encontre a possibilidade de existência na atividade.

A motivação, portanto, não é em si mesma uma entidade do psiquismo que só pode ser explicada por sua própria existência ou por fatores parciais como a afetividade ou os interesses extrínsecos ou mesmo intrínsecos do indivíduo. Para compreender-se a motivação deve-se poder articular o conjunto das condições materiais objetivas e subjetivas coordenadas com as características próprias do objetivo ou objeto da atividade.

A emergência do movimento psíquico humano não é em si mesmo uma potência a priori no indivíduo, mas deve ser produzida a partir do próprio processo de desenvolvimento das capacidades e da consciência. Decorre disso que a exigência de que uma criança tenha motivação para esta ou aquela atividade só faz sentido depois que se aferiu o desenvolvimento das capacidades necessárias para a realização consciente e do domínio das possibilidades de efetivação das operações necessárias à atividade. Fica assim, posta em questão a comum exigência de que a criança deva ter uma motivação natural, espontânea e individual, como se fosse inata a motivação para as coisas não naturais, isto é, culturais.

A exigência comum no processo educativo, que se manifesta sob a expressão "a criança tem que ter": limites, motivação, interesse, vontade, respeito, por exemplo, é acompanhada pela noção de que essas capacidades deveriam existir ou desenvolver-se naturalmente na criança, sem a intervenção inteligente do educador.

Assim, ocorre no desenvolvimento da criança um duplo aspecto em relação ao poder. Primeiro que o poder humano só se forma com o ensino e a aprendizagem das suas formas sociais, por meio da transformação das funções psíquicas naturais em culturais. Segundo, com a entrada na vida social produz-se na criança, sob pena de ela não se humanizar, a necessidade do poder, isto é, ela precisa adquirir o poder humano. A consequência do reconhecimento desta necessidade implica para o processo educativo, considerar o ensino e a aprendizagem como esse processo de formação do poder nos indivíduos. $O$ poder para realizar-se como ser humano.

Isso quer dizer que não é a simples aquisição das habilidades motoras, ou a capacidade de ler, escrever, contar etc. que é a finalidade última do processo de ensino. Muito além do ensino das habilidades motoras e intelectuais necessárias às práticas sociais, o ensino deve visar o indivíduo e sua realização como homem social. O homem social é aquele que sabe como realizar atividades da produção de sua vida e da vida da sua comunidade, mas vai além disso. Deve compreender o seu tempo histórico, deve poder influenciar nos rumos da vida coletiva e realizar suas necessidades pessoais de forma coerente com as da sua comunidade.

Desde o início do processo educativo, a formação do indivíduo deve ocorrer com a integração destes aspectos que lhe darão a possibilidade de vivências como uma experiência da integralidade de si como ser social. Isso quer dizer que, nas suas relações 
cotidianas o indivíduo pode experienciar e compreender o lugar que ocupa na sociedade, a sociedade como produto de sua atividade e sua personalidade como própria da sua comunidade, isto é, uma personalidade que não está em conflito com esta. Assim, a personalidade encontra as contradições de seu tempo e lugar, mas também encontra resolução comunitária para as contradições, sem que isso signifique a dominação ou do outro.

A possibilidade de ser social, nesse caso, ocorrerá como possibilidade de superação das relações cotidianas alienadas no âmbito de sua integração social. Se por conta da complexificação da vida social a desalienação no plano da universalidade da existência da humanidade não é possível, nos limites de sua comunidade isso já não é uma verdade. Somente com essa possibilidade de existência comunitária e consciente, como expressão de uma personalidade que reconhece e é reconhecido por sua integração social, é que a educação, o ensino e a aprendizagem adquirem sentido vital humanizador.

\section{A afetividade e a simbolização do poder}

A afetividade encontra aqui a expressão clara da proposição feita por Vigotski (1996, p. 299) na qual este afirma que "o afeto é o alfa e o ômega, o primeiro e último elo, o prólogo e o epílogo de todo o desenvolvimento psíquico". É justamente por meio da afetividade que ocorre uma valoração da relação do indivíduo com o seu meio, e depois, em relação a si próprio, isto é, a autovaloração que comumente conhecemos por autoestima. O valor da relação como mundo e a qualidade que esta adquire é a base de formação dos sentidos de orientação das próprias ações.

O valor da relação dá uma estimativa inicial do poder do indivíduo em uma situação e ao mesmo tempo uma estimativa de respostas do meio em relação a si próprio. Essa valoração afetiva ocorre toda vez que nas ações da atividade do indivíduo uma operação deixa de resolver-se automaticamente e aparece à consciência como impedimento, negação, falta de recursos pessoais, etc., isso é, como problema. Nesse momento ganha expressão não somente as capacidades intelectuais de organização e solução da problemática pelo sujeito, mas justamente qual é o poder pessoal que este tem para isso. Isso significa que o sujeito percebe não simplesmente as condições objetivas necessárias para a realização da sua atividade, mas, principalmente, qual é a possibilidade de expressão de suas necessidades pessoais na situação dada.

Nesse momento surge para o sujeito a integralidade do seu ser no mundo, e o ser do próprio mundo em relação a si. O sujeito e seu mundo aparecem para consciência como qualidade da relação vital, e a vivência ganha sentido. Nesse sentido, a relação com o entorno ganha relevância para a compreensão da formação da personalidade.

\section{Poder e entorno (plano interpsicológico)}

A experiência coletiva produz uma significação do mundo, e essa se constitui como uma concepção que serve de referência para os sujeitos de um determinado grupo. Essa concepção de mundo é, portanto, orientadora das ações grupais e individuais. Tanto o grupo quanto os indivíduos constroem suas concepções do mundo. Elas não se confundem absolutamente, porém, existem necessariamente imbricadas em suas determinações, isto é, tanto os indivíduos interferem na concepção coletiva como esta na do indivíduo. 
Essa concepção advém daquela integralidade do ser no mundo, de um indivíduo. Ela expressa, portanto, não exclusivamente um processo de produção racionalizada pelo pensamento, porém, inclui os afetos, as valorações e sentidos pessoais que vão desde o sentido biológico até os significados sociais da situação do indivíduo como sujeito das relações sociais. Como disse Vigotski (2000, p. 328-329),

Para nós a concepção do mundo é tudo aquilo que caracteriza a conduta
global do homem, a relação cultural da criança com o mundo exterior. O
animal carece de uma concepção de mundo assim entendida e tampouco a
tem, nesse sentido, a criança quando nasce. Nos primeiros anos de sua vida,
as vezes até o período da maturação sexual, não existe nele uma concepção
do mundo no verdadeiro sentido da palavra. É melhor uma atividade no
mundo que uma concepção do mundo. Atribuímos, portanto, ao termo
'concepção de mundo' um significado puramente objetivo da atitude da
criança frente ao mundo em que vive. (tradução nossa, grifo nosso)

Ainda que a criança não tenha uma concepção de mundo estruturada em termos conceituais mais complexos, pode-se dizer que existe sempre um sentido de percepção do mundo em seu conjunto, mesmo que este existe como uma unidade fragmentada, isto é, com ligações imprecisas, mas em coexistência.

É necessário compreender-se que essa concepção do mundo ocorre por um processo de desenvolvimento do próprio pensamento e expressa, a cada momento, a experiência coletiva como vivência individual. Assim, a experiência afetiva com o meio produz uma valoração, que inicialmente tendo um sentido biológico, adquire, como resposta do meio uma valoração pessoal, ou seja, a experiência sensível adquire a qualidade da resposta dada pelo meio para a atividade do sujeito.

Existem padrões culturais de comportamento que produzem uma forma relacional em torno da criança. Assim, quando muda a idade cronológica, mudam os modos de relações como um ideal cultural esperado para cada idade cronológica. (VIGOTSKI, 1996, p. 264). Portanto, as mudanças do entorno refletem-se como formas orientadoras do comportamento individual, ditam de alguma maneira e em determinada proporção aquilo que o sujeito pode ou não realizar como possibilidade de suas necessidades. A relação do entorno produz, em parte, a medida da consciência que a criança tem do mundo, dividindo-o inevitavelmente em um mundo existente e um invisível para ela, mas que a afeta de alguma maneira e de forma incompreensível, como um mundo estranho.

O entorno, para a criança, é fundamenta lente a relação que ela estabelece afetivamente, portanto, a compreensão da qualidade do entorno não se encontra nas qualidades aparentes deste, na sua materialidade, mas na qualidade afetiva que a criança estabelece com a objetividade, construindo um sentido para a sua vida (VIGOTSKI, 1996, p. 383/384).

$\mathrm{Na}$ dinâmica da existência social, na "situação social de desenvolvimento", encontraremos sempre as condições e situações oferecidas pelo entorno, e as capacidades psíquicas desenvolvidas nos indivíduos, como meios da autorealizarão e expressão da individualidade como relação de poder com o outro. Isso caracteriza a forma interpsicológica do poder. A harmonia dessas relações indica que a educação desenvolve-se como forma adequada de educação do indivíduo. 


\section{Entorno e personalidade (plano intrapsicológico)}

A experiência é condicionante do ser. Essa afirmação parte do ponto de vista com o qual se compreende que o ser humano individualiza-se no processo de seu desenvolvimento social (MARX, 2004, p. 107). Assim os modos de sentir e pensar, por exemplo, que caracterizam o seu ser social, são resultados das formas que constituem o entorno, mas são principalmente as formas sintetizadas emocionalmente pelo indivíduo como formas do seu próprio existir no mundo.

Assim, a criança muda com a experiência afetiva, emocional e cognitiva, adquirindo as qualidades do entorno e produzindo qualidades próprias que se expressam como meio de afirmação da sua existência material e psíquica. Cada indivíduo produz, em maior ou menor medida, um movimento de ação sobre o mundo transformando-o para adequá-lo às suas necessidades pessoais.

Por outro lado, mesmo quando alguns aspectos do entorno permaneçam o mesmo, a criança muda e estabelece uma nova relação com o ambiente. A mudança na forma como a criança se relaciona com as mesmas condições objetivas indica que houve uma transformação que envolve em unidade os aspectos afetivos, cognitivos e emocionais, caracterizando assim um modo particular de se relacionar que marca a sua personalidade.

A experiência emocional produzida em qualquer situação é o condicionante fundamental do desenvolvimento da personalidade. Os diferentes lugares que ocupa na relação grupal produzem na criança uma relação afetiva e emocional diferenciada, ainda que na mesma situação objetiva. Por isso, em um mesmo grupo a mesma situação causará um desenvolvimento diferenciado entre seus sujeitos, em relação à formação da personalidade.

Nesse sentido, foi dito acima que a criança existe em um mundo de contradições e que compreende parcialmente a realidade do mundo em que vive, também percebe a existência de um mundo estranho, incompreensível, e ocupa um lugar próprio na atividade grupal. Essa situação confere um significado especial à sua existência e o sentido pessoal ganha características particulares quando ocorre uma tomada de consciência de si. Surge assim, o sistema "eu", que é desenvolvido na relação da criança com o "outro" e tem no grupo um lugar relevante.

Segundo Leontiev (1978, p. 177) o problema psicológico do "eu" é um problema cognitivo sobre a realidade conhecida de si mesmo e se esse conhecimento sobre si próprio corresponde à realidade. Essa é uma questão de consciência de si como indivíduo e sujeito em uma situação de existência coletiva. A tomada de consciência de si no mundo marca o surgimento de um sistema de referência afetiva que coloca o sujeito no centro de sua vida, isto é, como uma situação me afeta e como eu me relaciono com a minha existência nela?

Esse sistema de referência sobre si em relação ao mundo é o centro da forma de agir particularizada que caracteriza a personalidade. Toda vez que houver uma contradição entre esse sistema e a situação dada, a tomada de consciência sobre si emerge como condição da adequação do sujeito e sua condição nas relações sociais. Essa percepção de si refere-se a que existe uma condição de si no mundo das relações sociais, que está em andamento. Assim, o "eu" aparece em relação ao "outro" como sujeitos da atividade social e como se afetam, segundo as suas ações. Isso possibilita afirmar que a existência da personalidade não se encontra no indivíduo, mas em suas relações e atividade social. Como disse Leontiev (1978, p. 178), 


\section{INTERFACES DA EDUCAÇÃO}

Temos visto que as diversas atividades do sujeito se entrecruzam e se ligam em elos com relações objetivas, sociais por sua natureza, nas quais o sujeito entra necessariamente. Esses elos, suas hierarquias, são as que forma esse secreto 'centro da personalidade' a que chamamos 'eu'; dito e outro modo, este centro não está no indivíduo, ou está sob a superfície de sua pele, se não em sua existência.

A autorealização como possibilidade de estabelecer múltiplas relações sociais, articulando-as em torno das suas necessidades e expressar uma ação de poder sobre o outro, indica que houve um desenvolvimento psicológico que se caracteriza como formação intrapsicológica.

A articulação entre as relações interpsicológicas e intrapsicológicas existem, segundo Vigotski (2000, p. 150) como uma "lei genética geral de desenvolvimento cultural." Toda a educação do indivíduo e inclusive a educação da personalidade estão submetidas a essa lei geral, que é caracterizada pela constituição das ações dos indivíduos na produção de situações e contextos sociais.

\section{O "eu" e o "outro" na dominação da atividade}

A criança é inserida paulatinamente na atividade social, aos poucos atribui-selhe pequenas ações que o inserem na relação social com os outros. Como já foi dito, desde o início esse lugar que a criança ocupa, como sujeito de ações, tem um valor que o relaciona aos outros. Isso constitui um conjunto de posições ocupadas na vida social que indicam o poder de agir em relação aos interesses coletivos (outros) e os interesses

pessoais (eu).

A contradição inicial para agir segundo suas próprias necessidades e interesses em relação com os interesses do meio social, é marcada pela absoluta falta de poder humano da criança. Isso significa que a orientação das ações iniciais da criança reflete um sistema impulsivo e reflexo de respostas aos sinais do meio objetivo e orgânico subjetivo. Essa condição a coloca em uma situação de dominação pelo outro, educador.

Com aqueles valores das relações com os outros se forma, então, um conjunto hierárquico de modos de agir e operacionalizar uma ação em uma dada situação, conforme as condições concretas objetivas e subjetivas. Assim, a relação "eu/outro" na atividade social expressa quais sejam as possibilidades de agir, o poder pessoal na resolução de problemáticas, o domínio da situação, e a situação de dominação em si.

O poder inicial para agir e expressar as necessidades que são pessoais e dão sentido a minha relação com o mundo, em uma situação de dominação, significa que o outro determina em muitos casos as possibilidades da autorealização individual. Não obstante essa dominação se faça necessária no começo da existência social, ao passo que a criança adquire as qualidades psíquicas humanas, próprias da sua integração social, o domínio das ações deverá ser transferido entre os sujeitos da atividade social. Essa transferência do domínio e a diminuição da dominação (controle do poder do outro) permite que ocorram relações cada vez mais equilibradas, para a satisfação das próprias necessidades.

Pode-se perceber, então, que a dominação entra em relação com a formação da personalidade, e esta, como vimos acima, significa a tomada de consciência de si nas atividades sociais. Nesse sentido, as formas como nas atividades grupais a dominação é efetivada, marca profundamente a formação da personalidade e as formas pelas quais 
um indivíduo agirá em relação às suas atividades. Se a dominação se efetivou como transferência do domínio e do poder para agir socialmente, teremos uma personalidade equilibrada nas relações sociais, sendo que o contrário também é verdadeiro.

A transferência do domínio das ações nas atividades sociais, implica em que no processo educativo formam-se na criança os conhecimentos e capacidades psíquicas condizentes com a sua realidade, isto é, conhecimentos e capacidades que correspondem aos da sua integração social. Assim um indivíduo, na qualidade de sujeito social, é capaz de orientar e controlar a sua atividade de forma adequada e corresponder às necessidades sociais e pessoais.

$\mathrm{O}$ fato de que os conhecimentos operacionais permitam ao sujeito agir adequadamente na situação dada, não implica que isso ocorra mecanicamente sem que este reflita a hierarquia de necessidades afetivas que constituem a sua personalidade. Quando, no processo educativo, a transferência do domínio das ações é efetivada adequadamente, o sujeito conhece e toma consciência dos momentos e modos adequados de expressar-se emocionalmente, sente que tem o poder para agir como integralidade biopsicosocial.

A expressão emocional, por sua vez, significa que um conjunto de afetos em uma dada situação e em relação ao lugar que o indivíduo ocupa nas relações sociais (seu poder social), adquirem, em síntese, um sentido vital. Expressa a tomada de consciência de si na relação com o meio social, e como orientar e controlar as ações individuais e da personalidade.

A partir da expressão emocional, pode-se compreender como transcorreu o processo educativo. Se as expressões emocionais da afetividade se adéquam às situações e condições sociais, se elas permitem que um indivíduo aja equilibradamente (não em conflito) diante das contradições da existência coletiva e das situações operacionais de sua atividade, compreende-se que as relações de dominação se dissiparam a contento e o indivíduo adquiriu um poder racional sobre as suas ações. Mas, por outro lado, se as expressões emocionais se mostram inadequadas, contraditórias com a realidade e conflituosas, percebe-se que há um predomínio de orientação pelos reflexos impulsivos e irracionais, o que indica que não houve transferência adequada do poder humano.

Daqui depreende-se, portanto, a importância das relações de poder e dominação na formação da personalidade em qualquer grupo humano que adquira o caráter educativo. A formação da personalidade é o principal escopo do processo educativo, porquanto esta indica o grau de desenvolvimento social que abarca não somente os aspectos cognitivos, porém, os afetivos e emocionais que vinculam o homem à sua vida social e lhe permitem uma tomada de consciência adequada à sua realidade. Disto decorre, então, o poder de crítica e orientação transformadora da sua realidade, de forma adequada tanto aos interesses pessoais quanto sociais.

\section{Considerações sociais}

Considerando o que foi dito até aqui se pode compreender que o grupo é inicialmente a condição de desenvolvimento da humanização do indivíduo, sendo assim, imprescindível para que este se constitua com conteúdos afetivo e emocionais, tanto quanto com cognitivos e intelectuais. O processo de individuação caracteriza-se pelo fato de que um indivíduo da espécie humana transforma-se, além disso, em indivíduo da sociedade humana, podendo orientar-se nesta como um ser pertencente e 
consciente de sua comunidade. Vem, por isso, constituir uma autoatividade, com suas próprias características e objetivada para a satisfação das novas necessidades criadas pela cultura.

Esse processo de desenvolvimento e individuação exige uma atividade específica, além da participação em outras atividades sociais, que é a educação. Por meio desta ocorre a organização do pensamento e formação de capacidades psicológicas específicas da cultura humana. Inclui-se nessa atividade a educação dos sentidos pessoais de orientação da autoatividade no tocante à manifestação das necessidades pessoais, isto é, dos requerimentos da existência integral do indivíduo como sujeito social, em cujas atividades forma-se a personalidade.

A personalidade se forma no processo educativo com a aprendizagem do uso dos recursos materiais e dos meios psicológicos para agir socialmente. Concomitantemente com essas condições ocorrem relações de poder e de dominação que inserem o indivíduo como sujeito nas ações sociais, e esta inserção produz uma significação sobre o valor de sua existência, e o da sua sociedade.

O grupo familiar é hoje o primeiro e mais importante formador da personalidade, sendo que neste, ocorre um direcionamento afetivo para a vida social produtiva e para as relações interpessoais. Isso se refere ao fato de que na família há uma predominância de relações afetivas que formam na criança uma concepção de mundo na qual ela se inclui em determinadas relações de poder e com isso dá um significado ao seu pertencimento na sua comunidade. No que concerne ao valor de sua própria existência, a personalidade é a expressão das necessidades criadas nesse processo e do poder para satisfazê-las.

Disso decorre que, além da formação para a vida social produtiva, a família deve, por necessidade da melhor formação para seus filhos, entender como a organização das relações grupais, no seu interior, são fundamentais para a educação da personalidade. Isso significa que a educação familiar, ou no grupo primário de inserção da criança no mundo social, tem importância fundamental na formação para o futuro do indivíduo, para uma vida social equilibrada. Ocorre, então, a formação de ações cooperativas e críticas em relação às transformações culturais necessárias ao desenvolvimento pessoal e social.

\section{Adendo às considerações: sobre a relação famílialescola}

A relação da família com a escola pode ser abordada tomando a atividade como base. Sabe-se que quando a criança passa a freqüentar a escola ela enfrenta uma nova estrutura de atividade. Se considerarmos que na estrutura da atividade humana ocorre uma divisão observável entre ações e operações, por outro lado uma parte de sua estrutura não é tão objetiva assim. As necessidades, os motivos e objetivos que também estruturam a atividade só podem ser abstraídos por uma pesquisa dos significados simbólicos que orientam os sujeitos que a realizam.

Como foi dito acima, na atividade familiar existe uma preponderância de relações afetivas e de poder que resultam na personalidade, na formação do indivíduo e de um sujeito social. Porém, ao ingressar na escola outros tipos e relações circunscreverão o entorno com o qual a criança se relaciona. Ocorrerão diferentes distribuições de ações e atribuições de responsabilidades referentes aos objetivos da atividade escolar. Surgirá um novo tipo de entorno. 
Aquela relação de objetificação que ocorre na relação educativa do adulto, agora professor, adquire outras características e metas, pois a atividade do professor está relacionada a outros interesses socioculturais e irá, portanto, produzir uma nova forma e estranhamento no quadro do mundo da criança. Várias expressões afetivas e emocionais contraditórias aparecerão como indício de uma confusão por parte da criança, porquanto ela existirá, agora, em dois entornos diferentes, com afetos e interesses diferentes.

Outra questão de muita importância é que nas relações familiares e também nas que antecedem a sua entrada na escola, desenvolve-se na criança um tipo específico de pensamento que está diretamente relacionado com as práticas do grupo familiar e dos grupos de crianças com as quais ela mantém amizades e pratica jogos e brincadeiras.

O pensamento empírico desenvolvido nessas atividades é suficiente para que a criança compreenda as relações que mantém com a família e com os grupos de amizade. Porém, ao ingressar no ambiente escolar, começa a surgir para ela a exigência de aprender a usar o pensamento teórico conceitual e científico. Um novo nível de contradições irá desenvolver-se como forma e organização inteligente da sua relação com o mundo objetivo e subjetivo. Uma nova forma de expressão das necessidades pessoais deverá ser formada e, aqui, pode-se falar então, que do ponto de vista afetivo a escola também deveria se preocupar com a formação da personalidade do estudante.

Assim, os desafios para a organização da atividade familiar e da escolar estão justamente em compreender no conjunto de suas atividades como será possível uma transição segura nessa mudança na estrutura da atividade da criança. Pois a criança continuará ocupando um lugar na família e começará ocupar outro na sociedade. Com a entrada da criança na escola o valor do seu lugar na sociedade se altera e, com isso, a autovaloração e novas perspectivas de futuro aparecerão para ela como novas necessidades, motivos e objetivos que alteram sobremaneira a estrutura da sua personalidade.

\section{Referências Bibliográficas}

DAVIDOV, V. La enseñanza escolar y el desarrollo psíquico: Investigación psicológica teórica y experimental. Tradución de Marta Shuare. Moscú: Progreso, 1988.

LEONTIEV, A. N. Actividad, conciencia y personalidad. Buenos Aires: Ediciones del Hombre, 1978.

. Uma contribuição à teoria do desenvolvimento da psique infantil. In: VIGOTSKII, L. S., LURIA, A. R., LEONTIEV, A. N. Linguagem, desenvolvimento e aprendizagem. 6 ed. Tradução Maria Penha Villalobos. São Paulo: Í́cone: Universidade de São Paulo, 1998.

MARX, K., Manuscritos econômico-filosóficos. Tradução Jesús Raniere, São Paulo: Boitempo Editorial, 2004.

MÉSZÁROS, I. Educação para além do capital. Tradução Isa Tavares. São Paulo: Boitempo, 2005.

VYGOTSKI, L. S. Obras escogidas III: Problemas del desarrollo de la psique. Traducción de Lidia Kuper. Madrid: Visor, 2000.

\begin{tabular}{|l|r|r|r|r|r|}
\hline Interfaces da Educ. & Paranaíba & v. 1 & n. 2 & p. 79-96 & 2010 \\
\hline
\end{tabular}


- Obras escogidas IV: Psicología infantil. Traducción de Lidia Kuper. Madrid: Visor, 1996.

2001.

. A construção do pensamento e da linguagem. São Paulo: Martins Fontes, 